\title{
¿DESPIDO IMPROCEDENTE DE VÍCTIMA DE VIOLENCIA DE GÉNERO O VULNERACIÓN DE SU DERECHO A LA INDEMNIDAD? (SOBRE LA STSJ CATALUÑA 9 FEBRERO 2017)*
}

\author{
Francisco Xabiere Gómez García \\ Investigador Contratado Predoctoral. Derecho del Trabajo y de la \\ Seguridad Social. Universidad de León
}

Resumen: La protección a la víctima de violencia de género en el ordenamiento español se despliega también sobre el ámbito laboral, incluyendo una serie de medidas que buscan garantizar su permanencia en el empleo como factor de autonomía personal. Una de las garantías principales es la declaración de nulidad del despido de las víctimas que hayan ejercido alguno de los específicos derechos laborales que el legislador les concede, al objeto de evitar las represalias empresariales ante las molestias que dicha situación les pudiera ocasionar. La STSJ Cataluña 9 febrero 2017 (rec. 6964/2016) sirve de ejemplo tanto del nivel de cobertura que actualmente se puede obtener como de sus limitaciones, por lo que se proponen ciertas mejoras para cumplir el mandato legal de evitar que cualquier circunstancia ligada a la situación de violencia de género pueda influir en la relación de trabajo.

Palabras clave: Despido; Violencia de género; Protección; Carga de la prueba; Nulidad
Abstract: The protection of the gender-based violence victim in the Spanish legal system also extends to the field of employment, including a series of measures that seek to guarantee their permanence in employment as a factor of personal autonomy. One of the main guarantees is the declaration of nullity of the dismissal of victims who have exercised one of the specific labour rights granted to them by the legislator, in order to avoid employer reprisals for the inconvenience that this situation could cause. The STSJ Cataluña 9 February 2017 (rec. 6964/2016) serves as an example both of the level of coverage that can currently be obtained and of its limitations, so certain improvements are proposed to comply with the legal mandate to prevent any circumstance linked to the situation of gender violence from influencing the work relationship.

Keywords: Dismissal; Gender-based violence; Protection; Burden of proof; Nullity

* Este artículo forma parte de la investigación "La relación laboral ante la violencia de género: protección y carencias de atención”, cofinanciada por el Fondo Social Europeo y la Consejería de Educación de la Junta de Castilla y León. 
I. Introducción - II. El supuesto de hecho - III. Fundamentación jurídica y fallo - IV. Análisis crítico - V. Conclusiones - VI. Bibliografía

\section{Introducción}

Las bajas, el absentismo, las incapacidades y el descenso de la productividad que se dan entre las mujeres víctimas de violencia de género, hicieron necesaria la articulación de toda una serie de medidas legislativas específicas para intentar dar una protección efectiva a este colectivo, habida cuenta de que para muchas de ellas el empleo es el único medio de autonomía personal e, igualmente, de valoración social. A través del reconocimiento de estos derechos, se procura paliar que la situación de violencia de género que padecen pueda perjudicar negativamente el desempeño de su actividad laboral, siendo su finalidad última el mantenimiento de la relación de trabajo, salvaguardándola de las implicaciones del fenómeno violento.

Mediante el estudio de la STSJ Cataluña 9 febrero 2017 (rec. 6964/2016) se puede valorar, en un caso real, el nivel de protección legal ofrecido y, si se considera necesario, plantear algunos cambios que mejoren dicha protección.

\section{El supuesto de hecho}

El litigio se refiere a una trabajadora que desempeñaba sus funciones como teleoperadora en una aseguradora, quedando extinguida su relación laboral por «despido disciplinario en base a disminución continuada y voluntaria del rendimiento en el trabajo, habiendo sido advertida previamente por los responsables de su servicio, así como por el gerente». En la fecha de la comunicación del despido, 24-07-2015, la empresa le propone por escrito la extinción indemnizada con reconocimiento de la improcedencia del mismo en un futuro acto de conciliación administrativa. Además, se da la circunstancia que la mujer tenía solicitadas las vacaciones para el inminente mes de agosto.

En el Juzgado de lo Social de Terrassa se constata que la actora viene sufriendo violencia de género en el ámbito familiar, existiendo condena penal contra su ahora ex esposo, de fecha 16-03-2015, la cual impone una pena de 4 meses de prisión por un delito de coacciones, con prohibición de comunicación y acercamiento a distancia menor a mil metros, durante los 12 meses siguientes. A consecuencia de estos hechos la víctima recibe asistencia psicosocial, desde el 09-06-2015, en el Centro de Atención a la Mujer del Ayuntamiento de Sabadell.

La empresa alega que la carta de despido fue entregada por la responsable de recursos humanos de la empresa, desplazada a tal efecto desde Madrid, la cual desconocía la condición de víctima de violencia de género de la mujer. Sin embargo, resulta probado que, en fecha 02-07-2015, la trabajadora había remitido comunicación, vía email, a uno de los responsables de su servicio, indicando que disponía de una orden de 
protección por agresión de su marido y que el juzgado le había entregado un teléfono directo con el policía asignado al caso, por lo que solicitaba un certificado de la empresa donde se informase de la dirección del centro de trabajo así como de los horarios de entrada y de salida, e igualmente, preguntaba la posibilidad de poder estacionar dentro de las instalaciones de la empresa y la documentación que, en su caso, sería necesario aportar.

El 07-07-2015, el responsable contesta con otro email remitiendo el certificado solicitado y comunicando que para el tema del parking se ponga en contacto con el Comité de Empresa, pues es quien realiza directamente la gestión del mismo. En realidad, el protocolo del aparcamiento establece que la solicitud se debe enviar a una dirección electrónica y esperar en lista de espera la posible asignación, lista que tramita un trabajador del citado Comité, pero cuyas decisiones finales las adopta la propia empresa.

El 28-07-2015 se intenta la conciliación administrativa con el resultado de «sin avenencia», tras ofrecer la empresa la reincorporación con el mismo salario y categoría, aunque sin precisar las condiciones del puesto ni la fecha de reincorporación. De resultas, la representación legal de la trabajadora presenta demanda sobre despido disciplinario, interesando la nulidad de la decisión extintiva. La sentencia de instancia, de 22-06-2016, estima parcialmente la demanda al no considerar acreditada la causa del despido, por lo que declara la improcedencia del mismo.

Contra dicha decisión la actora acude en suplicación al TSJ de Cataluña, solicitando la nulidad del despido por vulneración de derechos fundamentales, según los arts. 14, 15 y $24 \mathrm{CE}$ en relación con el art. 55.5 ET., dado que la demandante es víctima de violencia de género.

\section{Fundamentación jurídica y fallo}

La Sala examina este último artículo del Estatuto de los Trabajadores, el cual dispone que será nulo el despido, entre otros supuestos, en el caso «de las trabajadoras víctimas de violencia de género por el ejercicio de los derechos de reducción o reordenación de su tiempo de trabajo, de movilidad geográfica, de cambio de centro de trabajo o de suspensión de la relación laboral en los términos y condiciones reconocidos en esta ley».

De la dicción literal del mismo, entiende que no basta que quien sea objeto de un despido sea víctima de violencia de género para que, de modo inmediato y sin ningún otro requisito, sea calificado como nulo, sino que es preciso que además aquella haya pretendido ejercitar determinados derechos. Por lo tanto, en el presente caso no afecta si la empresa conocía o no dicha condición, pues la demandante en ningún caso ejercitó los mencionados derechos en los términos reconocidos legalmente, sino que se limitó a pedir una certificación que la empresa libró inmediatamente, además de solicitar información sobre la forma de acceder al parking, lo que no debe considerarse una petición concreta y formal. 
En cualquier caso, en vista de que la recurrente alega que se han vulnerado sus derechos fundamentales, el Tribunal infiere que este argumento implicaría que la verdadera razón del despido es la de querer ejercitar los derechos que la legislación laboral concede a las víctimas de violencia de género, actuando la empresa en represalia por dicho ejercicio, vulnerando así el art. $24 \mathrm{CE}$, el cual establece el principio de tutela judicial efectiva. La Sala remite a la doctrina del Tribunal Constitucional (STC 14/1993, de 18 de enero, rec. 1315/1989), la cual pone de manifiesto que del ejercicio de la acción judicial o de los actos preparatorios o previos al mismo no pueden seguirse consecuencias perjudiciales en el ámbito de las relaciones públicas o privadas para la persona que los protagoniza, lo que, en el ámbito de las relaciones laborales se traduce en la imposibilidad de adoptar medidas de represalia derivadas del ejercicio por el trabajador de la tutela de sus derechos -la denominada «garantía de indemnidad»-. En este sentido, añade que la medida disciplinaria del despido como respuesta al ejercicio de acción judicial también aparece expresamente proscrita en el art. 5.c) del Convenio núm. 158 de la OIT, ratificado por España el 26 de abril de 1985.

Entraría aquí en juego la doctrina constitucional sobre la inversión de la carga de la prueba $^{1}$, es decir, una vez justificada la concurrencia de indicios de que se ha producido violación del derecho fundamental o libertad pública, corresponderá al demandado la aportación de una justificación objetiva y razonable, suficientemente probada, de las medidas adoptadas y de su proporcionalidad (art. 181.2 LRJS). Sin embargo, la Sala niega que existan tales indicios al considerar que, en base al mencionado art. 5.c), la víctima «en ningún caso ha presentado una queja o participado en un procedimiento entablado contra la empleadora por supuestas violaciones de leyes o reglamentos, ni tampoco presentó ningún recurso ante las autoridades administrativas competentes», interpretando que simplemente pidió unas certificaciones e información, por lo que no procede la aludida inversión de la carga de la prueba.

Por todo ello, desestima el recurso de suplicación y confirma íntegramente la sentencia dictada por el Juzgado de lo Social.

\section{Análisis crítico}

Fue la Disposición adicional séptima de la Ley Orgánica 1/2004, de 28 de diciembre, de Medidas de Protección Integral contra la Violencia de Género (en adelante, LOMPIVG) la que modificó la letra b) del apartado 5 del artículo 55 del Estatuto de los Trabajadores ampliando la consideración de despido nulo para el supuesto de las trabajadoras víctimas de violencia de género «por el ejercicio de los derechos de reducción o reordenación de su tiempo de trabajo, de movilidad geográfica, de cambio de centro de trabajo o de suspensión de la relación laboral, en los términos y condiciones reconocidos en esta ley». Posteriormente, la trascendental Ley Orgánica $3 / 2007$, de 22 de marzo, para la igualdad efectiva de mujeres y hombres (en adelante,

1 Por todas, STC 101/2000, de 10 de abril, rec. 2652/1997. 
LOIMH), extendió esta protección al art. 53.4.b) ET, amparando así a la víctima de violencia de género tanto frente a despidos disciplinarios improcedentes carentes de causa como a los despidos objetivos que enmascaren esta ${ }^{2}$.

Lo primero que llama la atención es la deficiente técnica legislativa empleada en estos artículos, por cuanto se establece una sorprendente conexión de causalidad -que precisaría de una prueba específica-, a diferencia de lo que se dispone en los mismos para las trabajadoras embarazadas y las personas que ponen en práctica derechos referidos al tiempo de trabajo vinculados con los cuidados. Así, la doctrina ha cuestionado el objeto de una norma que considera nulo el despido de quien ha ejercido unos derechos y que se limita a disponer que así será si la extinción contractual se produce «por el ejercicio de los derechos» en cuestión, ya que el mero sistema indiciario, las reglas sobre desplazamiento del onus probandi y la garantía de indemnidad conducirían a resultado, no ya igual sino, más tuitivo ${ }^{3}$.

En cualquier caso, la literalidad del precepto parece no amparar la cualidad subjetiva de víctima por sí sola -aunque, como en este supuesto, esté acreditada mediante título habilitante- pues, aparentemente, la LOMPIVG solo ha extendido el sistema dual de calificación del despido (nulo o procedente) a aquellos casos donde la víctima efectivamente ha ejercido derechos, no protegiendo a las que optan por compatibilizar su situación y trabajo sin activar ninguno de ellos ${ }^{4}$, en un resultado paradójico en tanto que dicha ley tiene como finalidad declarada «garantizar derechos en el ámbito laboral y funcionarial que concilien los requerimientos de la relación laboral y de empleo público con las circunstancias de aquellas trabajadoras o funcionarias que sufran violencia de género» (art.2.d LOMPIVG). Para evitar esta situación, se ha hecho notar que el legislador pudo haber incluido en la cláusula de los artículos 55.5.b) y 53.4.b) ET una protección amplia y genérica ante despidos motivados por su condición de víctima, o bien haber incluido expresamente la de la violencia de género entre las causas de discriminación prohibidas del artículo $17.1 \mathrm{ET}$, adquiriendo así la calificación de discriminatorio, con la consecuencia de nulidad y falta de efectos de cualquier decisión o disposición basada en la situación de víctima de violencia de género ${ }^{5}$.

2 ÁlVAREZ CUESTA, H.: "La incidencia de la situación de violencia de género en las distintas vías de extinción del contrato de la trabajadora", en AA.VV. (SEMPERE NAVARRO, A.V., Dir. y MARTÍN JIMÉNEZ, R., Coord.): La extinción del contrato de trabajo, Cizur Menor, Aranzadi-Thomson Reuters, 2011, pág. 1236.

3 SEMPERE NAVARRO, A.V.: "Cinco casos recientes sobre colectivos vulnerables: prostitutas, extranjeros, víctimas de violencia de género, discapacitados, jubilados forzosos", Aranzadi Social, núm. 14, 2008, págs. 11-21.

4 SEMPERE NAVARRO, A.V.: "Aspectos sociolaborales de la LO 1/2004, de 28 de diciembre”, en AA.VV. (MUERZA ESPARZA J., Coord.): Comentarios a la Ley Orgánica de Protección Integral contra la Violencia de Género, Cizur Menor, Aranzadi, 2005, págs. 149-151.

5 PERÁN QUESADA, S.: "La protección de la trabajadora víctima de violencia de género ante el despido. Comentario a la Sentencia del TSJ de Cataluña (Sala de lo Social), de 3 de octubre de 2008", Aranzadi Social, núm. 16, 2009, págs. 33-40. 
Más allá de la eventual inadecuación entre espíritu protector y texto legal, es necesario destacar que este impedimento para que opere la nulidad cualificada, no obstante, no imposibilita que, si la motivación del despido proviene de la situación de violencia de género que padece la trabajadora, el despido pueda ser tachado de discriminatorio y, por tanto, calificado con una nulidad ordinaria, siempre y cuando la demandante aportase indicios razonables, los cuales en este proceso parece que podían existir, pues «la proximidad temporal o el conocimiento patronal se consideran como indicios de los cuales debieran derivar la aplicación de las reglas de distribución de la carga probatoria ante una posible vulneración derechos fundamentales» ${ }^{6}$.

En este sentido, llama poderosamente la atención que la Sala rechace la inversión de la carga de la prueba aduciendo el art. 5.c) del Convenio 158 de la OIT, obviando que tanto las responsabilidades familiares como el embarazo se enmarcan dentro de la letra d) del mismo artículo, al igual que el sexo, verdadera causa de discriminación indirecta en las situaciones de violencia de género, pues un despido empresarial por una circunstancia relacionada «que objetivamente se estuviera produciendo (disminución del rendimiento, ineptitud sobrevenida, incumplimiento de horario, etc.), en realidad situaría a la mujer en situación de desventaja con respecto al hombre puesto que, es la mujer la única que legalmente puede sufrir violencia de género y que, estadísticamente, de manera abrumadora es sujeto de violencia doméstica» ${ }^{7}$. Es necesario recordar que el principio hermenéutico del favor muliere está positivado en el art. 4 LOIMH y, como tal, debe observarse en la interpretación y aplicación de las normas jurídicas, y por ende también en el derecho disciplinario laboral, incluso aunque no sea derecho antidiscriminatorio ${ }^{8}$.

\section{Conclusiones}

Si bien la condición de víctima de violencia de género, «desde luego lamentable, no es un dato que automáticamente deba valorarse como reductor de su responsabilidad personal ${ }^{9}$-el propio art. 55.5 ET dispone que el despido no será nulo si se realiza por motivos no relacionados con el ejercicio de los derechos señalados-, la labor interpretativa juzgadora debe huir ineludiblemente de «interpretaciones autómatas de la norma a través de esa subsunción de lo fáctico en lo jurídico» ${ }^{10} \mathrm{y}$ contextualizarlo en una realidad material concreta, para así alcanzar una justicia real y no solo formal.

6 SEMPERE NAVARRO, A.V.: “Aspectos sociolaborales de la LO 1/2004, de 28 de diciembre”, en AA.VV. (MUERZA ESPARZA J., Coord.): Comentarios a la Ley Orgánica de Protección Integral contra la Violencia de Género, Cizur Menor, Aranzadi, 2005, pág. 150.

7 MENÉNDEZ SEBASTIÁN, P. y VELASCO PORTERO, T.: La incidencia de la violencia de género en el contrato de trabajo, Madrid, Cinca, 2006, pág. 119.

8 STSJ Cataluña 9 marzo 2018 (rec. 6987/2017).

9 STSJ Madrid 14 junio 2002 (rec. 1918/2002).

10 TORRES DÍAZ, M.C.: "La fundamentalidad del derecho a una vida libre de violencia de género: la necesidad de un marco jurídico conceptual/despatriarcalizador inserto en el texto constitucional”, Themis: Revista jurídica de igualdad de género, núm. 13, 2013, pág. 31. 
Por otra parte, en una sociedad como la nuestra, en la cual el trabajo posee un rol central, para las víctimas de violencia de género resulta de gran importancia el mantenimiento del empleo como una de las condiciones del disfrute de la ciudadanía social, entendida como medio y fin para conseguir su total protección, integración e inclusión ${ }^{11}$. Por ello, se hace necesario equiparar la protección de las trabajadoras víctimas de violencia de género a la de las trabajadoras embarazadas, es decir, activar el sistema dual (nulo/procedente) por lo menos desde que exista un título válido acreditativo de la situación de violencia, entendiendo que la LOMPIVG extiende su alcance a las relaciones de trabajo para, entre otras, evitar la propia pérdida del empleo como consecuencia del estado físico o anímico de la víctima e, incrementar así, el resultado negativo de este tipo delictivo ${ }^{12}$; pues lo contrario significa dar carta blanca a la parte empresarial para deshacerse de la víctima trabajadora, al coste de la improcedencia, antes de que la misma pueda activar alguno de los derechos laborales derivados de su situación.

Finalmente, ya que es la propia situación de violencia de género la que convierte a la víctima en sujeto tutelable ${ }^{13}$, y pareciendo evidente que quien sufre una situación así tenga, si quiera temporalmente, repercusiones en su capacidad para el trabajo, no estaría de más que la ley hubiese incorporado indicación sobre el rendimiento debido similar a la que se contiene en el art. 20.3 ET para los trabajadores discapacitados, respecto de los cuales el cumplimiento de sus obligaciones debe realizarse teniendo en cuenta su capacidad real ${ }^{14}$.

\section{Bibliografía citada}

AA.VV. (BENGOECHEA BARTOLOMÉ, M., Coord.): I Informe anual del Observatorio Estatal de Violencia sobre la Mujer, Madrid, Ministerio de Trabajo y Asuntos Sociales, 2007.

ÁLVAREZ CUESTA, H.: "La incidencia de la situación de violencia de género en las distintas vías de extinción del contrato de la trabajadora", en AA.VV. (SEMPERE

11 MONEREO PÉREZ, J.L. y TRIGUERO MARTÍNEZ, L.A.: "La protección socio-jurídica de la víctima de violencia de género", en AA.VV. (QUESADA SEGURA, R., Dir.): La perspectiva laboral de la protección integral de las mujeres víctimas de violencia de género, Granada, Comares, 2009, pág. 107.

12 VILA TIERNO, F.: "Medidas de mantenimiento de empleo para las trabajadoras víctimas de violencia de género", en AA.VV. (QUESADA SEGURA, R., Dir.): La perspectiva laboral de la protección integral de las mujeres víctimas de violencia de género, Granada, Comares, 2009, pág. 252.

13 AA.VV. (BENGOECHEA BARTOLOMÉ, M., Coord.): I Informe anual del Observatorio Estatal de Violencia sobre la Mujer, Madrid, Ministerio de Trabajo y Asuntos Sociales, 2007, pág. 132.

14 RODRÍGUEZ ESCANCIANO, S.: "Dificultades para la integración laboral de las mujeres víctimas de violencia de género", en AA.VV. (RODRÍGUEZ ESCANCIANO, S. y MARTÍNEZ BARROSO, M.R., Dirs. y ÁLVAREZ CUESTA, H., Coord.): La inserción laboral de las mujeres en riesgo de exclusión social, Valencia, Tirant Lo Blanch, 2015, pág. 153 . 
NAVARRO, A.V., Dir. y MARTÍN JIMÉNEZ, R., Coord.): La extinción del contrato de trabajo, Cizur Menor, Aranzadi-Thomson Reuters, 2011.

MENÉNDEZ SEBASTIÁN, P. y VELASCO PORTERO, T.: La incidencia de la violencia de género en el contrato de trabajo, Madrid, Cinca, 2006.

MONEREO PÉREZ, J.L. y TRIGUERO MARTÍNEZ, L.A.: “La protección socio-jurídica de la víctima de violencia de género", en AA.VV. (QUESADA SEGURA, R., Dir.): La perspectiva laboral de la protección integral de las mujeres víctimas de violencia de género, Granada, Comares, 2009.

PERÁN QUESADA, S.: “La protección de la trabajadora víctima de violencia de género ante el despido. Comentario a la Sentencia del TSJ de Cataluña (Sala de lo Social), de 3 de octubre de 2008", Aranzadi Social, núm. 16, 2009.

RODRÍGUEZ ESCANCIANO, S.: "Dificultades para la integración laboral de las mujeres víctimas de violencia de género", en AA.VV. (RODRÍGUEZ ESCANCIANO, S. y MARTÍNEZ BARROSO, M.R., Dirs. y ÁLVAREZ CUESTA, H., Coord.): La inserción laboral de las mujeres en riesgo de exclusión social, Valencia, Tirant Lo Blanch, 2015.

SEMPERE NAVARRO, A.V.: "Cinco casos recientes sobre colectivos vulnerables: prostitutas, extranjeros, víctimas de violencia de género, discapacitados, jubilados forzosos", Aranzadi Social, núm. 14, 2008.

— "Aspectos sociolaborales de la LO 1/2004, de 28 de diciembre", en AA.VV. (MUERZA ESPARZA J., Coord.): Comentarios a la Ley Orgánica de Protección Integral contra la Violencia de Género, Cizur Menor, Aranzadi, 2005.

TORRES DÍAZ, M.C.: “La fundamentalidad del derecho a una vida libre de violencia de género: la necesidad de un marco jurídico conceptual/despatriarcalizador inserto en el texto constitucional", Themis: Revista jurídica de igualdad de género, núm. 13, 2013.

VILA TIERNO, F.: "Medidas de mantenimiento de empleo para las trabajadoras víctimas de violencia de género", en AA.VV. (QUESADA SEGURA, R., Dir.): La perspectiva laboral de la protección integral de las mujeres víctimas de violencia de género, Granada, Comares, 2009. 